\title{
MS\&T Travels to Portland for 2019
}
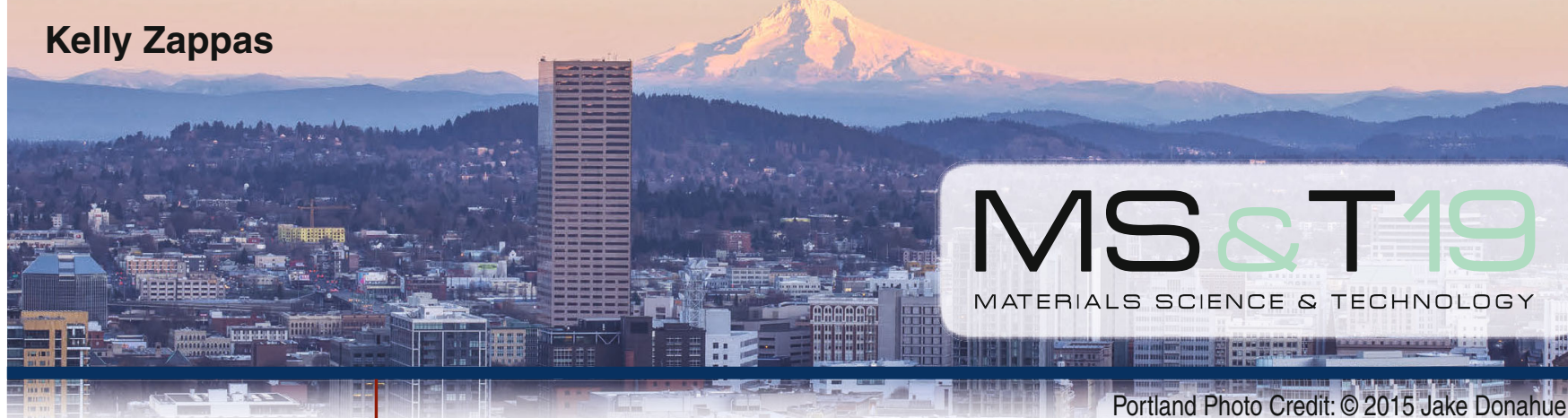

\section{Important MS\&T19 Deadlines}

- Discount Registration Deadline: August 30, 2019

- Discount Housing Deadline: September 5, 2019

Visit www.matscitech .org/MST19 for more details.

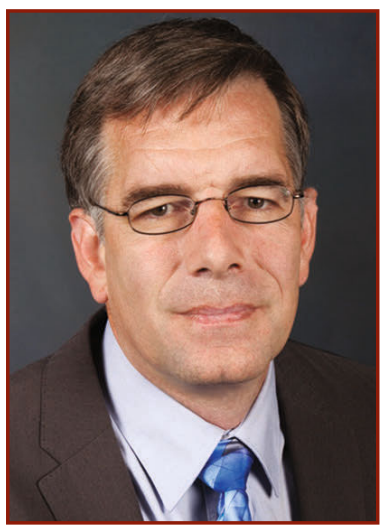

\section{Carl Cady}

TMS Representative to the MS\&T19 Program Coordinating Committee
For the 17th installment of the Materials Science \& Technology (MS\&T) conference and exhibition, MS\&T19 takes its multidisciplinary programming, technical exhibition, and networking events to a new location-Portland, Oregon-this fall, September 29 through October 3.

While it may be a new location, Portland fits in nicely with one of the overarching themes of the MS\&T conference series. One of several nicknames for the city is "Bridgetown," and MS\&T is known for its ability to create bridges between the various sectors, technologies, and societies within the materials science and engineering communities. (For a look at the city's other nicknames, see the "Portland Fun Facts" sidebar.)

MS\&T19 will feature presentations, courses, and events developed in collaboration with four materials-related societies: TMS, the American Ceramic Society (ACerS), the Association for Iron \& Steel Technology (AIST), and ASM International. What follows is a preview of this year's conference from a TMS perspective.

\section{Programming Highlights at MS\&T19}

Each year, the MS\&T program presents symposia that are divided into a dozen broad technical areas: Additive Manufacturing, Biomaterials, Ceramic and Glass Materials, Electronic and Magnetic Materials, Energy, Failure Analysis, Fundamentals and Characterization, Iron and Steel (Ferrous Alloys), MaterialsEnvironmental Interactions, Modeling, Nanomaterials, and Processing and Manufacturing.

Within these categories lie a number of technical symposia and sessions of interest to the TMS community. Carl Cady, technical staff member, Los Alamos National Laboratory, who serves as the TMS representative to the MS\&T Program Coordinating Committee, highlighted a few notable items from this year's program.

"There will be several sessions with presentations that talk about machine learning, which I believe is the next step in developing new materials and predicting material response," said Cady. "Along with computational material science, the path toward developing advanced materials seems well on the way toward predicting response then creation, rather than creation then characterization and using the characterization to inform models."

Because MS\&T provides a broad range of topics to choose from, Cady recommends that attendees explore the full program, suggesting that all attendees look at the Special Topics section, which includes some non-technical topics such as education and diversity and inclusion. "There are always interesting things to learn from our colleagues that don't necessarily overlap in the research topics that are of interest to us," said Cady.

Additional topics that may be of special interest to TMS members, he said, include 10 symposia focused on additive manufacturing topics, including sessions on titanium-based additive manufacturing, powder metallurgy, and additive manufacturing education.

This year's program will also 
feature two sessions on Metamorphic Manufacturing: Incremental Deformation Processing for Agile, High-Quality Metallic Component Production. In the area of steels, he pointed to three symposia that show synergy with our AIST counterparts: Advances in Understanding of Martensite in Steels, Formability and Fracture of Metal Sheets, and Thermomechanical Processing in Shaping and Forming of Steels.

"This will be the last partnered meeting with ASM for the foreseeable future and we hope that the joint programming seen by the partner societies' membership is interesting and informative," said Cady. "We hope to continue to be a society that leads the way in programming topic areas that are at the forefront of research and product development in the area of materials science."

For more perspectives on the developing program for MS\&T20, see "Previewing MS\&T20: A Roundtable with Program Organizers," also published in the August 2019 issue of JOM.

\section{Hansson to Deliver Distinguished Keynote Lecture}

Carolyn Hansson, professor of materials engineering at the University of Waterloo in Canada and a TMS Fellow, will deliver the TMS/ASM Joint Distinguished Lectureship in Materials and Society as part of the MS\&T19 plenary session planned for Tuesday morning, October 1.

Hansson's research has covered many aspects of environmental degradation of materials, particularly the corrosion and erosion of metals and alloys. Over the last 20 years, her major research focus has been the durability of infrastructure materials, particularly the chloride-induced corrosion of reinforcing bar and those properties of the concrete which affect this process. Her current research is focused on the application of corrosion-resistant alloys as reinforcing materials with a view to understanding the influence of the metallurgy on the corrosion resistance and prediction of the relative life-cycle costs of the different alloys.

Her presentation, "The Challenge of
100 Year Service-Life Requirement," will look at the materials challenges of meeting new standards that are under consideration to raise the service-life specification for reinforced concrete highway infrastructure from the current 75 years to 100 years or more.

The goals of these standards are to reduce financial and environmental costs and improve the sustainability of the system, but, in many locations, salt from seawater and de-icing agents limit the durability of reinforced concrete. The chlorides destroy the natural passivity of reinforcing steel in concrete and allow active corrosion, which eventually causes cracking and spalling of the concrete. De-icing agents containing calcium- or magnesium-chloride can attack the concrete directly. Her presentation will describe the research at Waterloo on identifying the most appropriate stainless steels to combat the chloride attack over the long term.

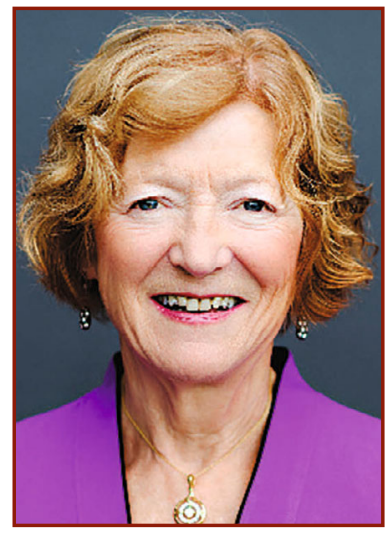

Carolyn Hansson

TMS/ASM Joint Distinguished Lecturer in Materials and Society

\section{MS\&T19 Exhibit Activities}

MS\&T19 will feature an extensive exhibition of products and services, so attendees should schedule time to browse the exhibits on Tuesday, October 1, and Wednesday, October 2. All MS\&T19 attendees are invited to meet with exhibitors at the Exhibitor Networking Reception from 4:00 p.m. to 6:00 p.m. on the first day of the exhibit.

Lunch will be served both days in the exhibit hall, offering attendees an additional opportunity to meet with exhibitors and network with colleagues. Lunch is included with the registration rate for full-conference attendees.

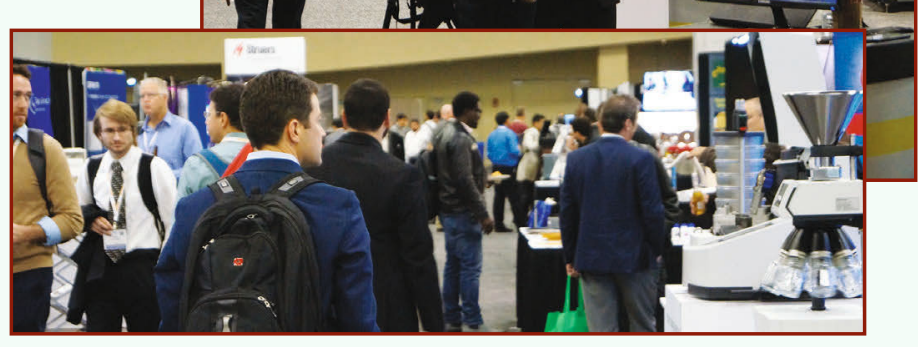




\section{Additive Manufacturing Workshop Returns for MS\&T19}

Since 2015, attendees at MS\&T conferences and TMS Annual Meetings have learned from the collected knowledge of a team of experienced instructors at the Additive Manufacturing Materials and Processes Workshop. This popular course will be held once again on Sunday afternoon, September 29.

Instructors David L. Bourell, University of Texas at Austin, Sudarsanam Suresh Babu, University of Tennessee-Knoxville, and Kirk Rogers, The Barnes Group Advisors, will lead the workshop, which is designed to familiarize participants with current

\section{Join Us at MS\&T19}

Come and experience the new conference venue, the broad technical program, distinguished lectures, and special events for yourself. Registration and housing are now open for MS\&T19.

TMS members are encouraged to book housing at the Doubletree by Hilton Portland, which will serve as the headquarters hotel for TMS and AIST activities, including committee meetings. additive manufacturing (AM) processes; current AM practice for metals, polymers, and ceramics; modeling of AM processes, microstructural evolution, and service properties; and current challenges and research opportunities. The program is intended for those who have some familiarity with AM processes, but want to learn more.

Sign-up for this workshop is available through the conference registration form at www.matscitech.org/MST19. Please note that registration for the full MS\&T19 Conference and Exhibition is not required to attend the course.

The deadline to book housing at the MS\&T discounted room rate is September 5, 2019, and the deadline to register for the MS\&T meeting and educational events at the early discounted rate is August 30, 2019.

Visit www.matscitech.org/MST19 to register, secure housing, and access additional program details, and plan to join us in Portland for MS\&T19.

\section{Portland Fun Facts}

The city of Portland and the Oregon Convention Center are new venues for the MS\&T conference series, so to introduce you to this new location, here are a few pieces of trivia about our host city, provided by the Travel Portland website:

- Portland's nicknames include City of Roses, Stumptown, Bridgetown, and Beervana.

- Portland is home to both the world's smallest dedicated park (Mill Ends Park at $61 \mathrm{~cm}$ across) and the largest box of doughnuts (found at the 24-hour doughnut shop Voodoo Doughnut).

- Worth noting for shoppers, Oregon is one of only five U.S. states with no sales tax.

- And because MS\&T is all about bridges: Portland's Hawthorne Bridge is the oldest vertical-lift bridge in the country; it turned 100 in 2010. The nearby Steel Bridge celebrated its 100th anniversary in 2012.

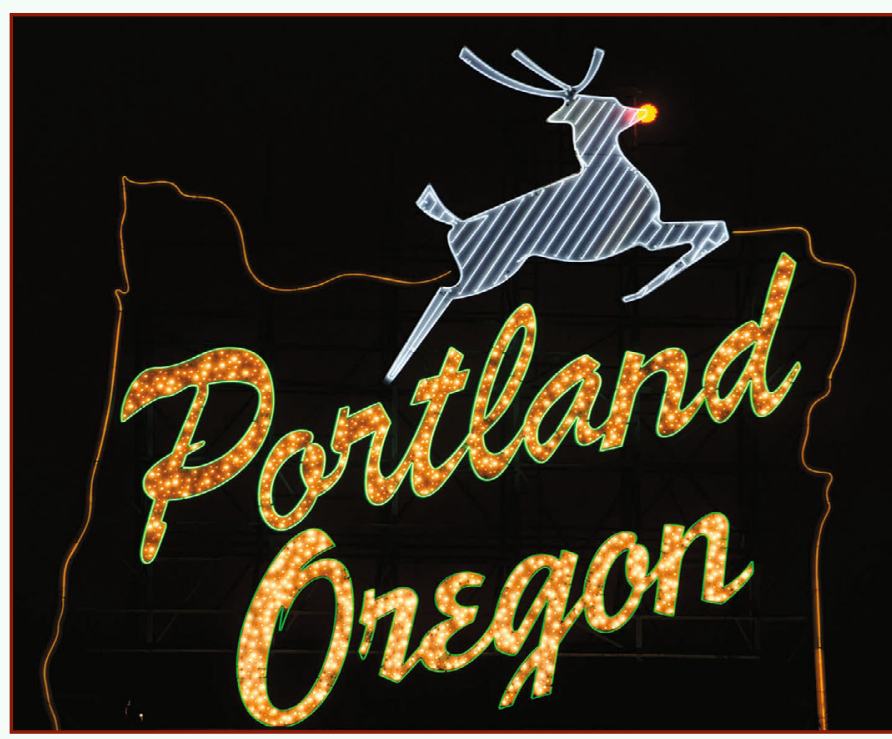

Photo Credit: Travel Portland \& Torsten

Portland also boasts one of the largest bookstores in the world (Powell's City of Books), a leading science museum (The Oregon Museum of Science and Industry), and a number of notable gardens, including the Lan Su Chinese Garden, the International Rose Test Garden, and the Portland Japanese Garden. Learn more about local attractions at www.TravelPortland.com. 